\title{
Synthesis and performance of polyurethane/silicon oxide nano-composite coatings
}

https://doi.org/10.1515/secm-2019-0012

Received March 5, 2018; accepted January 9, 2019

\begin{abstract}
Chrysotile asbestos has excellent physical and chemical properties, but its high biotoxicity is very damaging to human health, due to its durability, high aspect ratio, and the exist of iron. By simple chemical treatment of chrysotile asbestos, silicon oxide nanofibers rich in hydroxyl groups on the surface can be prepared.
\end{abstract}

In this study, we synthesized a series of polyurethane/silicon oxide nano-composite coatings with special performance following a blending method that introduced silicon oxide nanofibers into polyurethane. Measurement results revealed that, silicon oxide nanofibers can be used as reinforcing filler to increase the hardness, shear strength, wear resistance, thermal stability and chemical resistance of polyurethane coatings. And the optical performance test results indicate that the transmittance of the polyurethane coating decreased with increasing of silicon oxide nanofibers contents. However, the ultraviolet shielding effect of the polyurethane coating was improved to a certain extent with the addition of silicon oxide nanofibers.

Keywords: polyester polyol; polyurethane; silicon oxide nanofibers

\footnotetext{
${ }^{\star}$ Corresponding Author: Junrui Zhang: School of Science, Zhijiang College of Zhejiang University of Technology, Shaoxing, 312030, Zhejiang, China, Tel.: +86 575 81112729. Fax.: +86 575 81112729., E-mail: jrzhang@zjc.zjut.edu.cn

Guojun Jiang, Tianhao Huang, Yu Gao: School of Science, Zhijiang College of Zhejiang University of Technology, Shaoxing, 312030, Zhejiang, China

Weihua Yu: School of Science, Zhijiang College of Zhejiang University of Technology, Shaoxing, 312030, Zhejiang, China Research Group for Advanced Materials and Sustainable Catalysis (AMSC), State Key Laboratory Breeding Base of Green ChemistrySynthesis Technology, Institute of Industrial Catalysis, College of Chemical Engineering, Zhejiang University of Technology, Hangzhou 310032, China
}

\section{Introduction}

Silicon oxide nanofibers have useful properties, and they have a great potential for application and development in new materials $[1,2]$. In the structure of silicon oxide nanofibers, atoms silicon and oxygen are in amorphous rules arranged in a three-dimensional reticular structure, showing a one-dimensional mesoscopic morphology. And they typically have diameters less than 100nm, and lengths ranging from micrometers to millimeters. Silicon oxide nanofibers can be used as a reinforcing material of polymers, offering new special performance to such materials. For example, the density of silica nanofibers is smaller than that of common fillers, which is helpful for reducing the specific gravity of composites. In addition, the thermal conductivity is higher than that of common fillers, which is beneficial to the heat dissipation of composites and increasing the thermal stability of composites. Moreover, the refractive index is closer to that of common resins, which is beneficial for preparation of transparent composites. Finally, they have high chemical stability and can be introduced into matrix material via chemical bonding due to the hydroxyl groups at the surface [3-6].

Chrysotile asbestos is a kind of silicate mineral, with an ideal molecular structure of $\mathrm{Mg}_{6}\left(\mathrm{Si}_{4} \mathrm{O}_{10}\right)(\mathrm{OH})_{8}$. It has excellent properties, such as heat resistance, tensile resistance, and transparent under visible light, and is used widely in modern industries such as construction, chemical industry, metallurgy, and machinery. Chrysotile asbestos has a one-dimensional tubular structure, and its low cost of natural output is unmatched by other artificial materials. However, the biological toxicity of chrysotile asbestos causes great damage to human health with chronic contact, the adverse environmental and health effects of asbestos are very well documented in literature [711]. Therefore, it is important to inactivate the harmful properties of chrysotile asbestos while, taking advantage of its low cost and unique performance. MaravelakiKalaitzaki et al investigated potential detoxification of pure chrysotile asbestos via a combined treatment of oxalic acid dihydratewith silicates, such as tetraethoxysilane (TEOS) and pure water glass, the results indicated that all 
of the applied treatments destructed the chrysotile structure, yielded silica with amorphous phase and each of the proposed formulations can be applied for the detoxification of asbestos [12]. Willenbring et al examined whether exudates from bacteria and fungi can alter chrysotile and lower its toxicity, results indicated that siderophore can remove iron from chrysotile fibers at natural concentration levels, and organic acid exudates did not remove iron from chrysotile fibers [13].

In this study, we examined silicon oxide nanofibers rich in hydroxyl groups on the surface prepared from chrysotile asbestos via chemical dispersion in anionic surfactant, and then followed a hydrochloric acid leaching method to remove the $\mathrm{Mg}$ - $(\mathrm{OH}) \mathrm{O}$ octahedral geometry and other metal ions [14]. Finally, we added them to a polyurethane matrix following a simple blending method and, synthesized a series of polyurethane/silicon oxide nano-composite coatings containing different weights of silicon oxide nanofibers, and investigated, the effects of the silicon oxide nanofibers on the properties of the polyurethane coating.

\section{Materials and methods}

\subsection{Raw Materials}

Adipic acid (AA), trimethylol propane (TMP), and 1,6hexanediol (HDO) were purchased from Alfa Aesar (USA). 1,4-cyclohexanedicarboxylic acid (1,4-CHDA) and 1,4cyclohexanedimethanol (1,4-CHDM) were obtained from SK Chemicals (Korea). Isophorone diisocyanate (IPDI) trimer (Desmodur Z4470) was supplied by Bayer Corporation (Germany). BYK141 (BYK Chemie, Germany) was used as a leveling agent. Silicon oxide nanofibers were supplied by the team of Professor Qiming Feng in Central South University (Changsha, China). All otherreagents were of analytical grade.

\subsection{Polyester polyol synthesis}

Polyester polyol was synthesized via a polycondensation reaction using AA, 1,4-CHDA, HDO, 1,4-CHDM, and TMP in a monomer molar ratio of 1:9:2.15:8.62:2.15. The reaction was performed in a 500-mL reactor equipped with a mechanical stirrer, nitrogen purging device, and Dean-Stark trap used for separating water and xylene. The reaction mixture was stirred continuously, and the reaction temperature was gradually increased to $210^{\circ} \mathrm{C}$, until the polyester resin reached an acid number below 1 (mg KOH/g resin). Then, the solvent was removed and the resin was cooled to room temperature. The acid number and hydroxyl number of the polyester was measured according to ASTM methods D1639-90 and D1957-09, respectively [15, 16].

\subsection{Preparation of polyurethane/silicon oxide nano-composite coatings}

Polyester polyol was dissolved in butyl acetate, and silicon oxide nanofibers was added and, dispersed in the mixture with a high speed disperser at $2000 \mathrm{~min}^{-1}$ for $10 \mathrm{~min}$. Then, trimer of IPDI was mixed in the presence of a leveling agent $(0.1 \mathrm{wt} \%$ of reactants (polyester polyol, silicon oxide nanofibers and trimer of IPDI) and solvent (butyl acetate)) and catalyst (dibutyltin dilaurate, $0.01 \mathrm{wt} \%$ of reactants and solvent). The molar ratio of functional groups $(\mathrm{NCO} / \mathrm{OH})$ in the system was 1.2:1. The solid content of the system was kept at 39 40 wt $\%$. The composite coating was prepared by casting the solution onto iron plates that had been degreased with acetone. The cast film was maintained at a thickness of $0.2 \sim 0.3 \mathrm{~mm}$ with a drawbar, and was cured at $80^{\circ} \mathrm{C}$ for $24 \mathrm{~h}$. The cured films were kept under ambient atmospheric conditions for 7 days before testing and characterization were performed.

\subsection{Characterization}

Gel permeation chromatography (GPC; Series-200; Perkin Elmer, USA) was used to determine the molecular weight and molecular weight distribution of the polyester resin. Fourier transform infrared spectroscopy (FTIR) analysis was performed with a VECTOR-33 (Bruker, Germany) with, a spectral scanning range was $400 \sim 4000 \mathrm{~cm}^{-1}$.

Wide Angle X-ray diffraction (WAXD) patterns were obtained on Bruker-D8 ADVANCE at room temperature ( $\mathrm{Cu}$ radiation, $40 \mathrm{kV} / 40 \mathrm{~mA}$ ). Angel $2 \theta$ was scanned from $3^{\circ}$ to $50^{\circ}$ with the step size of $0.02^{\circ}(2 \theta)$ and 0.1 s/step.

The aggregation structure of silicon oxide nanofibers was detected on Transmission Electron Microscope (TEM, Hitachi H-600, Hitachi Corporation). Samples were diluted with anhydrous ethanol and dripped on the copper wire mesh covered with acetate before tested.

The chemical composition of silicon oxide nanofibers was detected on Atomic Absorption Spectrophotometer (WFX-120; Beijing Beifen-Ruili, China).

Reverse impact resistance, flexibility, shear strength, abrasion resistance and shore hardness were performed according to GB/T 1732-93 [17], GB/T 1731-93 [18], 
GB/T10007-200 [19], GB/T1768-2006 [20] and GB/T5311999 [21], respectively.

Dynamic mechanical analysis was performed on a dynamic mechanical thermal analysis system (DMA 242, NETZSCH, Germany) using standard dumbbellshaped samples. The glass transition temperature $\left(\mathrm{T}_{g}\right)$ was measured in the stretching mode using a heating rate of $3^{\circ} \mathrm{C} / \mathrm{min}$ and a frequency of $1 \mathrm{~Hz}$ in the temperature range of $120^{\circ} \mathrm{C}$ to $150^{\circ} \mathrm{C}$.

Optical transmittance was tested on an ultravioletvisible spectrophotometer (LAMBDA950, PerkinElmer, USA) with an optical wavelength range of 200 900 nm.

\section{Results and discussion}

\subsection{Characterization of polyester polyol}

Fig. 1 shows the infrared spectrum of the polyester resin. A strong and wide peak at $3535 \mathrm{~cm}^{-1}$ represented the stretching vibration absorption peak of hydroxyls in the polyester resin. The absorption peaks at $2937 \mathrm{~cm}^{-1}$ and $2837 \mathrm{~cm}^{-1}$ were the asymmetric and symmetric stretching vibrations of $-\mathrm{CH}_{2}-$. The absorption peak at $1732 \mathrm{~cm}^{-1}$ was the stretching vibration of $-\mathrm{C}=\mathrm{O}$. The absorption peaks at $1452 \mathrm{~cm}^{-1}$ and $1383 \mathrm{~cm}^{-1}$ represented the deformation vibration of $-\mathrm{CH}_{2}$ - The vibrational absorption at $1169 \mathrm{~cm}^{-1}$ represented $\mathrm{C}-\mathrm{O}$ in polyester. The vibrational absorption at $1038 \mathrm{~cm}^{-1}$ represented $\mathrm{C}-\mathrm{O}-\mathrm{C}$. Finally, the vibrational absorption at $752 \mathrm{~cm}^{-1}$ represented $\left(\mathrm{CH}_{2}\right), \mathrm{n} \geq 4$ in polyester. The infrared analysis showed that hydroxyl terminated polyester resin was synthesized. The acid value was $0.76 \mathrm{mg} \mathrm{KOH} / \mathrm{g}$, and the hydroxyl value of polyester resin was $90.7 \mathrm{mg} \mathrm{KOH} / \mathrm{g}$, as tested according to ASTM methods D1639-90 and D1957-09, respectively. The molecular weight and molecular weight distribution of polyester resin was $2854 \mathrm{~g} / \mathrm{mol}$ and 1.26, respectively, which were measured via GPC.

\subsection{Structural characterization of the silicon oxide nanofibers}

Fig. 2 shows the infrared spectrum of the silicon oxide nanofibers. The strong and wide peak at $1092 \mathrm{~cm}^{-1}$ was the antisymmetric stretching vibration. The peaks at $800 \mathrm{~cm}^{-1}$ and $471 \mathrm{~cm}^{-1}$ represented the symmetric stretching vibration of Si-O. The peak at $3645 \mathrm{~cm}^{-1}$ represented the antisymmetric stretching vibration of $-\mathrm{OH}$, which exists in the chemical structure water. The weak peaks near $1632 \mathrm{~cm}^{-1}$

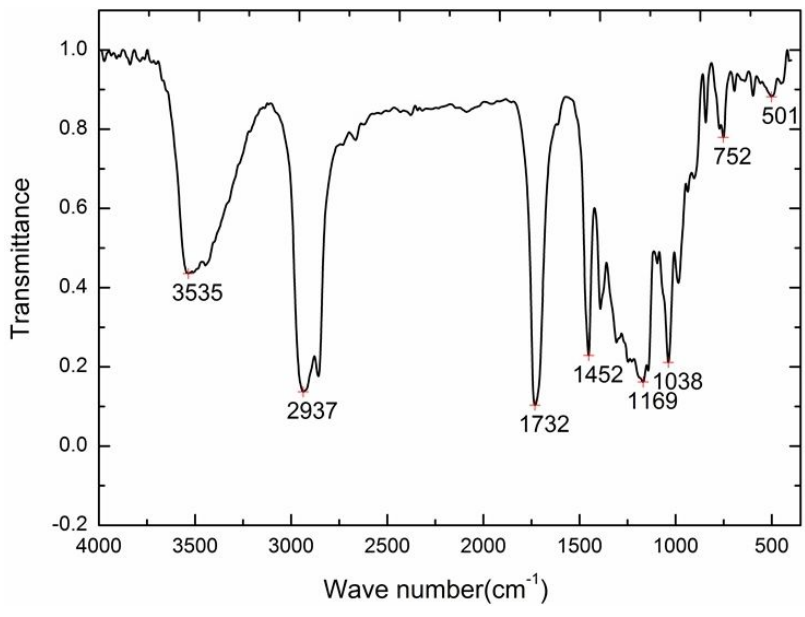

Figure 1: FTIR spectra of polyester polyol.

(unlabeled) represented the $\mathrm{H}-\mathrm{O}-\mathrm{H}$ bending vibration, which was the adsorbed water on the silicon oxide surface. Finally, the bending vibration absorption peak at $959 \mathrm{~cm}^{-1}$ was $\mathrm{Si}-\mathrm{OH}$. The absorption peak at $2928 \mathrm{~cm}^{-1}$ disappeared after calcination, which might have been caused by the residual chemical dispersants in the silicon oxide nanofibers [14, 22, 23]. Fig. 3 shows the wide angle $x$ ray diffraction of silicon oxide nanofibers, which shows a broad diffraction peak with low intensity at $2 \theta=15 \sim 30^{\circ}$, indicating that silicon oxide nanofibers synthesized in our experiment were basically amorphous structure. The aggregation structure of silicon oxide nanofibers was showed in Fig. 4. The natural output of chrysotile asbestos have fibrous shape with diameter of dozen nanometers to hundreds of nanometers. Silicon oxide nanofibers prepared from chrysotile asbestos via chemical dispersion in anionic surfactant and hydrochloric acid leaching basically preserved the structure of chrysotile asbestos, the surface of silicon oxide nanofibers was smooth and dispersed uniformly. The results showed that silicon oxide nanofibers were polycrystalline structure, dispersed uniformly, surface was smooth and contained a large amount of hydroxyl groups and, which could be used as reinforcing filler for polymer materials.

\subsection{Mechanical properties of the nano-composite coatings}

Table 1 shows the mechanical properties of the nanocomposite coatings (different contents of silicon oxide). A small amount of silicon oxide nanofibers had great influence on the mechanical properties of the polyurethane coating. Silicon oxide had a clear enhancement effect on 


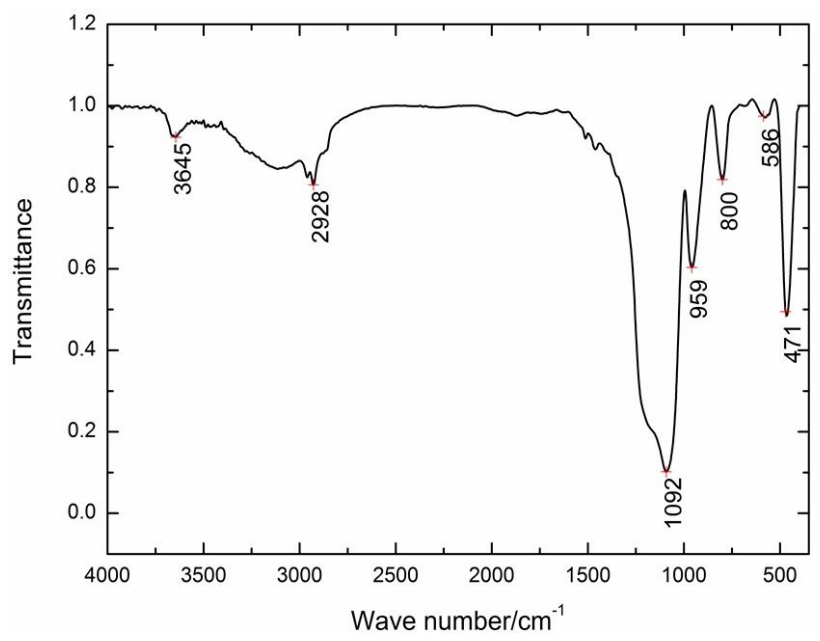

Figure 2: FTIR spectra of silicon oxide nanofibers.

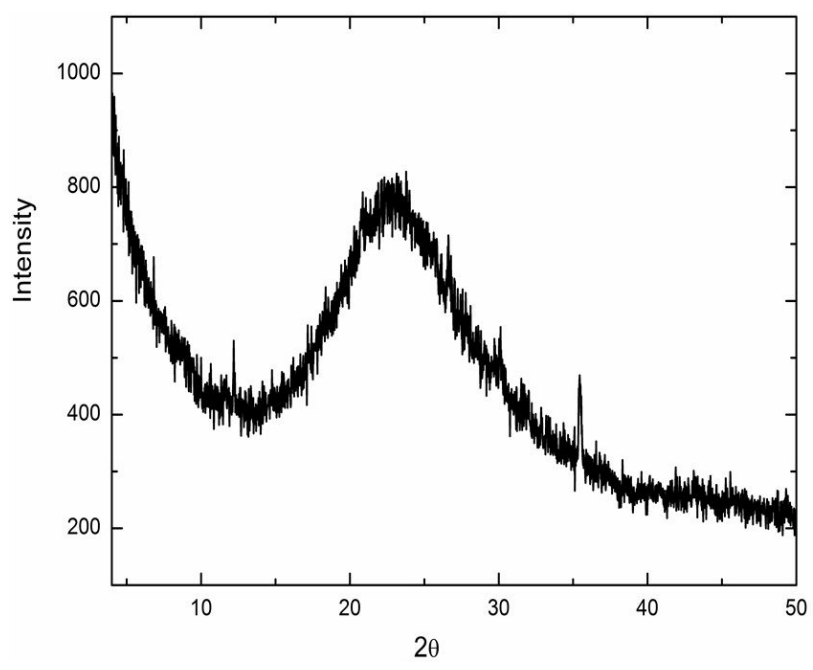

Figure 3: Wide Angle X-ray diffraction of silicon oxide nanofiber.

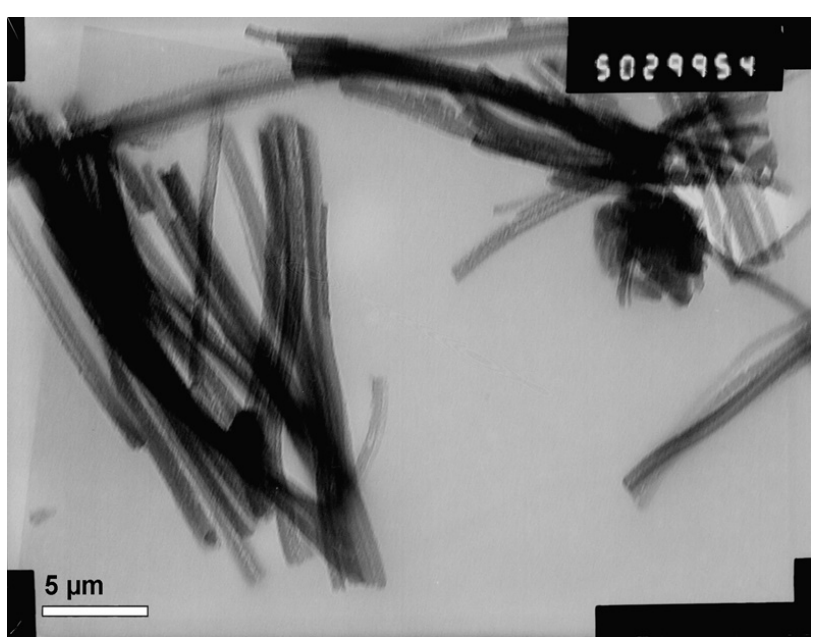

Figure 4: TEM of silicon oxide nanofibers.
Table 1: Mechanical properties of polyurethane/silicon oxide nanocomposite coatings.

\begin{tabular}{ccccc}
\hline Sample & $\begin{array}{c}\text { Impact } \\
\text { resistance } \\
(\mathrm{kg} . \mathrm{cm})\end{array}$ & $\begin{array}{c}\text { Flexibility } \\
(\mathrm{mm})\end{array}$ & $\begin{array}{c}\text { Shore A } \\
\text { hardness }\end{array}$ & $\begin{array}{c}\text { Shear strength } \\
(\mathrm{MPa})\end{array}$ \\
\hline $\mathrm{PU}$ & 90 & 1 & 65.2 & 49.1 \\
$0.2 \%$ & 90 & 1 & 65.6 & 50.3 \\
$0.4 \%$ & 85 & 1 & 65.9 & 51.2 \\
$0.6 \%$ & 80 & 1 & 66.8 & 53.5 \\
$0.8 \%$ & 70 & 1 & 67.6 & 55.5 \\
$1 \%$ & 65 & 1 & 68.2 & 56.3 \\
$2 \%$ & 60 & 1 & 72.5 & 60.2 \\
\hline
\end{tabular}

the hardness and shear strength of the composite coating, although the polyurethane matrix already had high hardness and shear strength. This was because the surface of the silicon oxide nanofibers were rich in hydroxyl groups, which had a great reinforcing effect on the polymer. However, the impact strength decreased with the addition of silicon oxide, possibly because the reinforcing effect of the silicon oxide gave the coating a higher hardness and lower toughness.

\subsection{Abrasion resistance of the nano-composite coatings}

The weight loss of the composite coating decreased as the content of silicon oxide increased (Fig. 5), and, the abrasion resistance of the polyurethane increased with the addition of silicon oxide (GB/T 1768-2006). The increase in the hardness gave the coating surface better abrasion resistance (Table 1). Therefore, the abrasion resistance of the coating could be improved by adding silicon oxide nanofibers.

\subsection{Chemical resistance of the nano-composite coatings}

Table 2 shows the chemical resistance of the nanocomposite coatings. Nano-composite polyurethane coatings had excellent chemical resistance properties. This was because silicon oxide nanofibers were stable in acids and alkalis, and they had good endurance to acids and alkalis in addition to hydrofluoric acid and strong alkali. Therefore, the chemical resistance of the nano-composite 


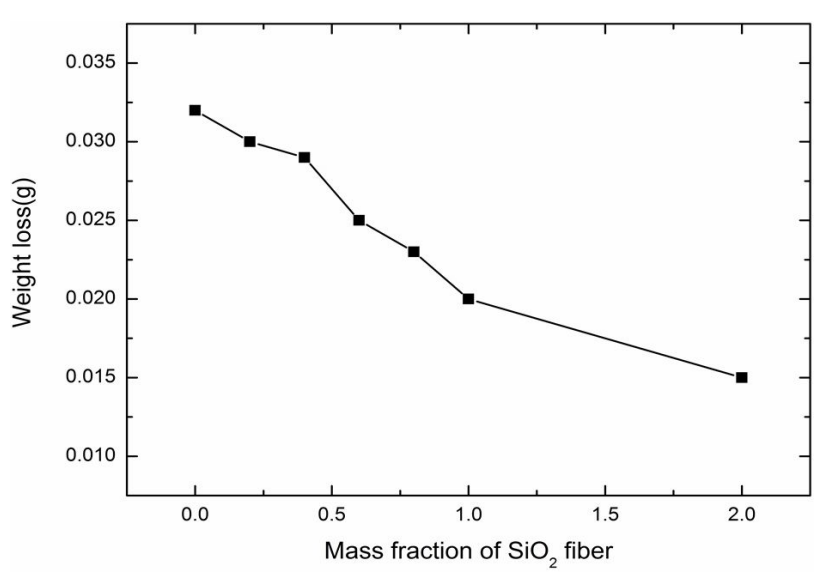

Figure 5: Abrasion resistance of polyurethane/silicon oxide nanocomposite coatings.

Table 2: Chemical resistance of polyurethane/silicon oxide nanocomposite coatings $\left(23^{\circ} \mathrm{C}, 7\right.$ days).

\begin{tabular}{|c|c|c|c|c|c|c|c|}
\hline Compound & $0 \%$ & $0.2 \%$ & $0.4 \%$ & $0.6 \%$ & $0.8 \%$ & $1 \%$ & $2 \%$ \\
\hline $\mathrm{H}_{2} \mathrm{SO}_{4}, 5 \%$ & 4 & 5 & 5 & 5 & 5 & 5 & 5 \\
\hline $\mathrm{NaOH}, 10 \%$ & 4 & 5 & 5 & 5 & 5 & 5 & 5 \\
\hline Toluene & 5 & 5 & 5 & 5 & 5 & 5 & 5 \\
\hline Xylene & 5 & 5 & 5 & 5 & 5 & 5 & 5 \\
\hline Acetone & 5 & 5 & 5 & 5 & 5 & 5 & 5 \\
\hline $\begin{array}{l}\text { Methyl ethyl } \\
\text { ketone }\end{array}$ & 5 & 5 & 5 & 5 & 5 & 5 & 5 \\
\hline
\end{tabular}

coatings was improved with the addition of silicon oxide nanofibers.

\subsection{Water absorption of the nano-composite coatings}

In this test, the polymer films were immersed in distilled water for $72 \mathrm{~h}$, then took out and, subsequently wiped their surface water with filter paper. The weight increase percentage was calculated using the following expression: $\mathrm{W}_{\text {increase }}=[(\mathrm{M}-\mathrm{m}) / \mathrm{M}] \times 100 \%$, where $\mathrm{M}$ is the sample weight after immersion in distilled water and, $m$ is the sample weight after being dried in the oven (Table 3). The water absorption of the composite coating slightly increased with different qualities of added silicon oxides. This might caused by the rich hydroxyl groups on the surface of silicon oxide nanofibers which, did not form a dense crosslinking with polyurethane matrix

\subsection{Dynamic mechanical analysis of the nano-composite coatings}

Fig. 6(a) and (b) display the storage modulus $\left(\mathrm{E}^{\prime}\right)$ and $\tan \delta$ of the polyurethane/ silicon oxide nanofibers composite coatings at different temperatures, respectively. It can be seen from Fig. 6(a) that the storage modulus of polyurethane coatings embedded with silicon oxide nanofibers were higher than that of a pure polyurethane coating at temperatures over $10^{\circ} \mathrm{C}$, which was probably because of the strong interaction between organic and inorganic phases in composite coatings. And there was no significant change in storage modulus of polyurethane after different amounts of silicon oxide nanofibers were added, but a slight increase was observed for polyurethane with $0.4 \mathrm{wt} \%$ silicon oxide nanofibers at temperatures over $45^{\circ} \mathrm{C}$. Fig. 6 (b) shows that, the Tg of polyurethane coating increased with the addition of silicon oxide nanofibers, and the composite coating had the highest $\mathrm{T}_{g}$ value when the silicon oxide nanofiber concentration was $0.4 \mathrm{wt} \%$. Adding more, silicon oxide resulted in a decrease in $\mathrm{T}_{g}$, where the degree of reduction was inversely proportional to the amount of silicon oxide added. This was probably because the amount of silicon oxide was small, and the surface hydroxyl groups were cross-linked with isocyanate, increasing the $\mathrm{T}_{g}$ of the composite. However, large amounts of silicon oxide were likely readily aggregated in the polyurethane matrix, resulting in the incomplete reaction of isocyanate with silicon oxide, and the interaction among the aggregated silicon oxide particles inhibited other silicon oxide particles reacting with isocyanate, thereby decreasing the influence on the $\mathrm{T}_{g}$ of the composite coating. Overall, as the silicon oxide content increased, the inhibition decreased and $\mathrm{T}_{g}$ increased to a certain degree $[24,25]$.

\subsection{Optical properties of the nano-composite coatings}

Fig. ?? shows the optical properties of the polyurethane/silicon oxide nano-composite coatings. The light transmittance of the coating decreased as the addition of silicon oxide nanofibers increased. The transmittance decreased sharply, and the surface became black as the quality of silicon oxide nanofibers reached or exceeded $1 \mathrm{wt} \%$, possibly due to the presence of some $\mathrm{Fe}, \mathrm{Mg}$, or other metal ions in the silicon oxide nanofibers causing a, difference in the refractive index between metal ions and polyurethane matrix due to light scattering on the polyurethane surface, resulting in a significant 

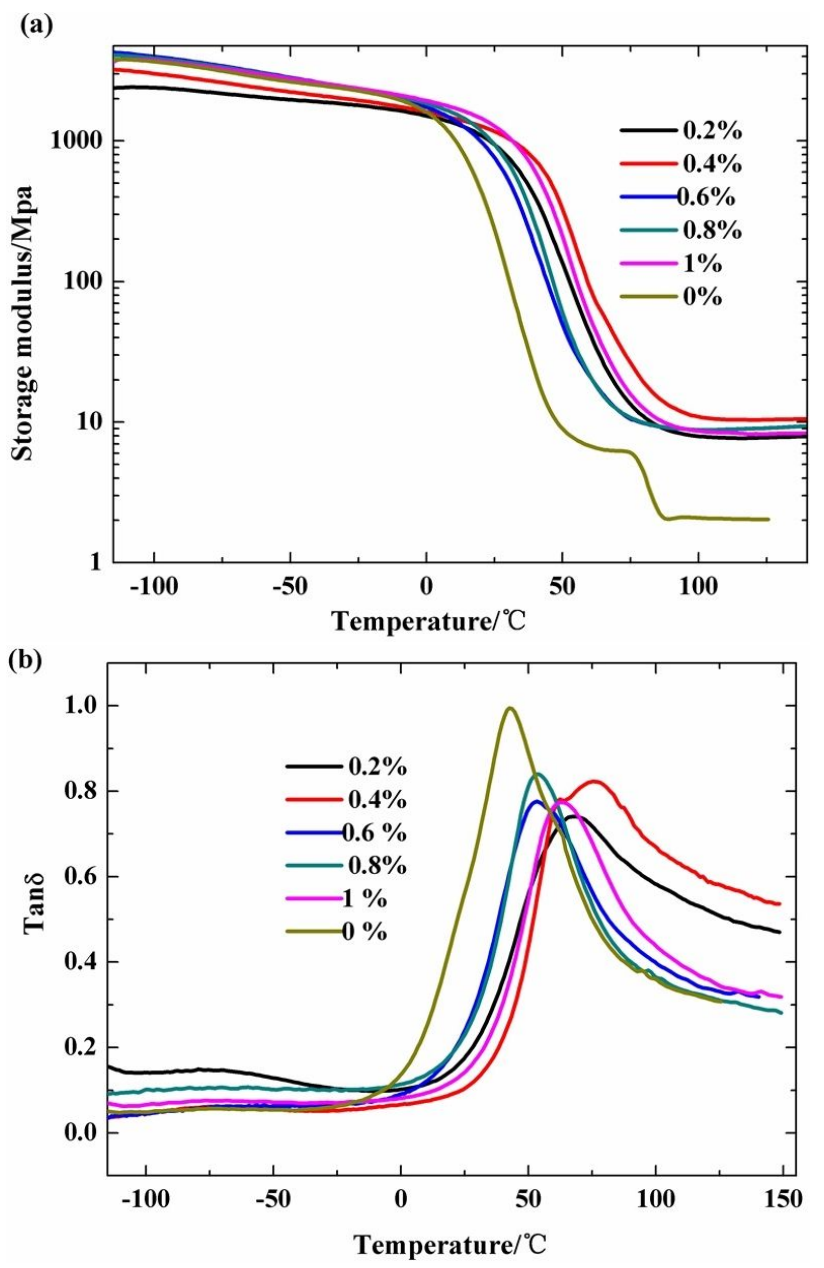

Figure 6: (a) DMA storage modulus vs. temperature at $1 \mathrm{~Hz}$ and (b) the corresponding $\tan \delta$ of polyurethane/silicon oxide nanocomposite coatings.

decrease in transparency (Table 4). Therefore, to make a nano-composite coating with better transmittance, the amount of silicon oxide nanofibers should be controlled below $1 \mathrm{wt} \%$.

Table 3: Water absorption of polyurethane/silicon oxide nanocomposite coatings.

\begin{tabular}{ccccccc}
\hline Time & $0 \%$ & $0.4 \%$ & $0.6 \%$ & $0.8 \%$ & $1 \%$ & $2 \%$ \\
\hline 7 days & 0.30 & 0.33 & 0.36 & 0.34 & 0.32 & 0.35 \\
& & & & & & \\
14 days & 0.32 & 0.33 & 0.38 & 0.35 & 0.31 & 0.35 \\
& & & & & & \\
21 days & 0.33 & 0.34 & 0.39 & 0.35 & 0.32 & 0.36
\end{tabular}

Table 4: Metal element content of silicon oxide nanofiber.

\begin{tabular}{cccccc}
\hline Metal element & $\mathrm{Ca}$ & $\mathrm{Al}$ & $\mathrm{Mg}$ & $\mathrm{Fe}$ & $\mathrm{Pb}$ \\
& & & & & \\
\hline Content $(\mathrm{wt} \%)$ & 0.26 & 0.11 & 0.24 & 2.00 & $<0.005$ \\
\hline
\end{tabular}

\section{Conclusions}

Silicon oxide nanofibers rich in hydroxyl groups on the surface were prepared via the simple chemical treatment of serpentine asbestos. From this, we synthesized a series of polyurethane/silicon oxide nano-composite coatings with special performance following a simple blending method that introduced silicon oxide nanofibers into polyurethane. Silicon oxide nanofibers rich in hydroxyl groups on their surface were ideal reinforcing fillers that could improve the hardness, shear strength, wear resistance, thermal stability and chemical resistance of the coating; however, the toughness of the coating declined with increasing addition of silicon oxide nanofibers. The light transmittance of the coating decreased with increasing addition of silicon oxide nanofibers, possibly caused by the large difference in the refractive index of the polyurethane matrix and metal ion residues in the silicon oxide. The addition of silicon oxide nanofibers improved the ultraviolet light shielding effect. The simple chemical treatment of chrysotile make it as a reinforcing material for polymers, which expanding the scope of chrysotile applications, offering some new special characteristics to such materials.

Acknowledgements: This research was supported by Zhejiang Provincial Natural Science Foundation of China (LQ18E030014, LQ18E030013, LQ19F050004 and LQ14E030004 ), the National Natural Science Foundation of China (21504079).

\section{References}

[1] Jin CK, Won JH. Sensors 2010, 10, 4083-4099.

[2] Li T, Zeng W, Wang Z. Sensors \& Actuators B Chemical 2015, 221, 1570-1585.

[3] Jiang XC, Herricks T, Xia YN. Nano Letters 2002, 2, 1333-1338.

[4] Chen GM, Wu LX, Xu JH, Xu GW, Huang YP. Science and Engineering of Composite Materials 2018, 25, 603-610. 
[5] Kar S, Chaudhuri S. Solid State Communications 2005, 133, 151 155.

[6] Chen Z, Wang YX, He HP. Solid State Communications 2005, 135, 247-250.

[7] Yamamoto T, Kida A, Noma Y, Terazono A, Sakai S. Waste Management 2014, 34, 536-541.

[8] Feder IS, Tischoff I, Theile A, Schmitz I, Merget R, Tannapfel A. European Respiratory Journal 2017, 49, 02534-2016.

[9] Kradin RL, Eng G, Christiani DC. American Journal of Industrial Medicine 2017, 60, 963-967.

[10] Turci F, M, Tomatis M, Mantegna S, Cravotto G, Fubini B. Journal of Toxicology and Environmental Health, Part A 2010, 73, 368377.

[11] Loomis D, Dement J, Richardson D, Wolf S. Occupational Environmental Medicine 2010, 67, 580-584.

[12] Valouma A, Verganelaki A, Maravelaki-Kalaitzaki P Gidarakos E. Journal of Hazardous Materials 2016, 305, 164-170. ‘

[13] Mohanty SK, Gonneau C, Salamatipour A, Pietrofesa RA, Casper B, Christofidou-Solomidou M, Willenbring JK. Journal of Hazardous Materials 2018, 341, 290-296.
[14] Liu K, Feng QM, Yang YX, Zhang GF. Journal of the Chinese Ceramic Society 2007, 35, 164-169.

[15] ASTM D1639-90, Standard Test Method for Acid Value of Organic Coating Materials.

[16] ASTM-D1957 - 2009 - Hydroxyl Value of Fatty Oils and Acids.

[17] GB/T 1732-93, Determination of impact resistance of film.

[18] GB/T 1731-93, Determination of flexibility of films.

[19] GB/T 10007-2008, Rigid cellular plastics-Determination of shear strength.

[20] GB/T1768-2006, Method of test for abrasion resistance of paint films.

[21] GB/T 531-1999, Rubber-Determination of indentation hardness by means of pocket hardness meters.

[22] Wypych F, Schreiner WH, Richard EJr. J Colloid Interface Sci 2004, 276, 167-173.

[23] Fonseca MG, Oliveira AS, Airoldi C. J Colloid Interface Sci 2001, 240, 533-538.

[24] Yang CH, Liu FJ, Liu YP, Liao WT. J Colloid Interface Sci 2006, 302, 123-132.

[25] Zhang SW, Liu R, Jiang JQ,Yang C, Chen MQ, Liu XY. Progress in organic coatins 2011,70, 1-8. 